\title{
Major Problems and Implementation Strategies of Early Immersion Bilingual Teaching of Children English
}

\author{
Xiuling Liu \\ College of Foreign Languages, Xi'an University, Xi'an Shaanxi, 710065, China
}

Keywords: Children English immersion teaching, Problems, Implementation strateties

\begin{abstract}
In our country, children English immersion teaching focuses on building an all-English learning environment for children so that they can "immerse" themselves in the English environment and acquire English naturally. However, the children English teaching in China is still faced with the problems such as lack of qualified English teachers and lack of children English language environments. Through exploring the problems in early immersion teaching of children English, this paper proposes some strategies to better implement such teaching mode so as to help children acquire English better.
\end{abstract}

\section{Introduction}

As a brand-new helpful teaching mode, the immersion teaching, which first arose in Canada in 1960s, refers to directly using the language which is not the mother tongue of learners as the teaching language. This teaching mode was introduced to China in the early $21^{\text {st }}$ century and has been carried out in some kindergartens of China. Maximally teach children whose mother tongue is Chinese in English in the kindergarten so that they can immerse themselves in an English environment for a whole day or half a day and thus they can have a good knowledge of English and Chinese. Immersion teaching not only requires teachers to face children with the second language but use the second language to teaching the second language as well as part of discipline curriculum. That is to say, the second language is not only the learning content but also the learning tool. This changes the traditional foreign language teaching method where a foreign language is only taken as a discipline.

\section{Theoretical basis and teaching mode of immersion teaching}

As shown in the results of scientific researches over recent years, there is a "critical period" (also called the best sensitive period) for children to acquire languages. Human beings' ability of acquiring languages decreases with the increase in ages after the critical period. There is also a critical period for the acquisition of a second language, so one's work will be doubled after the critical period. Immersion, which is a language acquisition theory, is the best way for children's early learning of a second language. Acquisition is a natural learning mode. In the immersion environment, children's acquisition of a second language is like their acquisition of their mother tongue. In meaningful language communications, they can naturally develop the ability of acquiring a language through understanding a language. Children can acquire English and communicate in English in a relaxing and pleasant situation. As shown in linguistic studies, effective language learning shall be carried out through interactions. Language communications are very vital for language learners, because people obtain their ability of fluent speaking from natural acquisition of meaningful interactive communication activities instead of direct teaching and syntactic formation training.

The English immersion teaching mode highlights the tool role of target language through "direct learning and similar acquisition”, effectively combines the target language learning with the learners' cognitive activities, and enhances the acceptability, understandability, interestingness and applicability of target language in a visual, vivid and interesting way. 


\section{Necessity and feasibility for children to learn English}

\section{Necessity}

With gradual internationalization of today's society, as an all-purpose language in the world, English has been listed in the require courses in elementary and higher educations. To cultivate talents with international competitiveness, English teaching from childhood will be the irresistible trend. Thus, English teaching for children is not only the need of the society but also the need of the era.

Today's society is ceaselessly marching to globalization, so it is badly in need of high-quality talents with a high knowledge level. Faced with such a trend, we can only pin our hope on children. Therefore, nowadays, children education is not only to cultivate high-level talents but also to enhance the quality level of the whole people. Besides, children English learning, which is an activity promoting their intelligence, plays a role in promoting children's language and cognitive development. In children English teaching, teachers can design different teaching activities to let children to learn oral English in a relaxing and natural way and to form preliminary language sense and interest, which lays a solid foundation for their future learning in reading stage. It is thus can be seen that it is very important to carry out English education for children.

\section{Feasibility}

Language is a very complicated phenomenon, but children's speed and success degree of acquiring their mother tongue are surprising. They can command their mother tongue in several years even without learning it consciously. According to the result of psychological study by Chomsky, a linguistician, "children are gifted with the language acquisition device and their ability of learning a language is shown in the first day after their birth, so a two-year-old child can communicate with people through language.” It is thus clear that it is feasible to carry out English teaching for children.

\section{Advantages and disadvantages in children's early immersion bilingual teaching}

\section{Advantages}

There is a critical period for language acquisition (both the mother tongue and a foreign language).Although one can learn a language in any age stage, age is a significant factor determining whether one can successfully learn a foreign language. Generally speaking, the period prior to adolescence (critical period from 2 to 12 years old) is the physiological active period of language learning. In this period, one's brain has a strong plasticity, so one can acquire a language in a natural and relaxing way. Therefore, teaching a foreign language in a scientific way can not only help children to learn a foreign language more easily in future but also can generate an optimal stimulation for children's brain so as to promote their intellectual development.

From the perspective of the scientific reseraches in biligual education, overseas biligual education has gone through a long research course of more than 100 years, and theoretical systems and practice patterns suitable for their basic national conditions have been established. It can be seen that biligual education is practically feasible, so English education shall be put in the position of mother tongue education. Education shall be started from childhood and English education shall also be started from childhood.

Recent studies show that the period from 1.5 to 3 years old is the critical period for chidren to learn a language; in this period, children are language learning"geniuses" and they have a very strong imitation ability, are not shy and have no pressure of homework, so learning English from childhool has more advantages than disadvantages.

\section{Disadvantages}

Although it can be seen from the relationship of age and foreing language learning that early childhood is the physilogical active period for English learning, a kindergarten shall determine the actual age of learning a foreign language based on the practical conditions of its teachers and physical resources. Improper bilingual teaching for children is likely to cause confusiona in both their language system and thinking, and even cause aphasia in a severe condition, so children shall learn Chinese first before learn other languages. 
Although studies show that early childhood is the critical period of language learning, children cannot transform the relationship between two languages due to their age. Besides, at present, most bilingual kindergartens in China are non-standard, so harmful hidden troubles may be left for their future English learning without correct English input (pronunciation, language sense, interest etc.). For this reason, it is required to create favorable learning conditions of both hardware and software so as to obtain double results with half the work.

\section{Major problems in early immersion bilingual teaching of children English}

\section{Weak bilingual faculties for children English}

At present, children English teachers are graduates majoring in pre-school education with certain English knowledge or graduates majoring in English teaching. The former has some difficulty in English language when carrying out all-English teaching while the latter is not able to do the work of children education well. Although some colleges have offerred English pronunciation, children English teaching and other courses for the students majoring in children education, the students don't pay sufficient attention to them. In addition, no effect can be guaranteed. Due to the lack of systematic English curriculum setting, students also lack the ability to carry out all-English teaching, so they usually emphasize knowledge teaching in their teaching process without taking games as the principal activity forms. If this continues this way, children will lose interest in English learning.

\section{Lack of sufficient children English learning environment}

A kindergarten's English language environment mainly involves kindergarten decorations, creation of English language atmosphere etc. As far as English teaching is concerned, kindergarten decorations mainly refer to highlighting the application of English in classrooms or within the scope of children activities, or writing sentence patterns frequently used in daily life. However, children English is dominated by listening and speaking, so such decorations are useless if they are not utilized by the teachers. Therefore, kindergarten decorations shall be replaced periodically closely according to the teaching progress so that they can really serve the teaching.

\section{Failure to integrate children English into life}

In most kindergartens, their English teaching for children is only limited to the classroom teaching and English teaching is finished after class. Teachers teache them in English for almost a whole class and children also respond, indicating that they understand their teachers' language. However, after the activity, both teachers and students speak Chinese instead of English when they go to the bathroom, drink water, participate in activities and take lunch.

\section{Strategies of improving immersion bilingual teaching of children English}

\section{Pay attention to cultivating bilingual children English teachers}

To provide children with sufficient and effective English inputs are two essential conditions for English immersion teaching. The sufficent input means that the English input in unit time shall meet children's need. The effective input means that such English input shall be absorbed by children and can promote their English outputs.

Improve children English teacher's oral English proficiency

For children, teachers' languages are their learning examples, so whether the teachers' pronunciation is standard, whether their expression is correct and whether their languages are normalized will directly influence children's language outputs. Many teachers, who organize English immersion teaching activities, are not graduates majoring in English, so they have some defects in their pronunciation. Besides, some teacher's pronunciation is affected by dialects or other factors. To pursue standard pronunciation, teachers can concentrate their efforts on the following aspects: (1) listen to records of original edition and simulate their pronunciation; (2) ask teachers with standard pronunciations to help them correct their pronunciation; (3) record their own voices and compare them with the original edition. 


\section{Enhance the understandability of language input}

The so-called "comprehensible inputs" refer to the comprehensible language materials heared or read by learners. The difficulty of such materials should be a little higher than the learners' current language level. Language materials inputted only including the knowledge already commanded by learner are not significant for language learners. If language materials inputted are too difficult, they cannot be comprehended. Krashen thought simple language inputs are not sufficient, because learners need "comprehensible language inputs" and this is the necessary condition for language acquisition. When choosing teaching contents, teachers shall try to choose those closely related to children's life to stimulate children's learning interest, help them to establish relevant associations and help them comprehend new knowledge better. Meanwhile, teachers can create story scenarios by using puppets, headwears and other props to visualize abstract content and help children comprehend and command languages.

\section{Actively create English language learning environment in kindergartens}

\section{Create an English langage physical environment suitable for children}

The English language environment refers to providing children with proper operational materials and space on the premise of meeting their needs and complying with their characteristics of bilingual learning so as to trigger the interactions between children and environment, support children's game and exploration activities and thus promote their bilingual learning. A favorable environment plays a role in supporting children's active learning and developing their language ability. For instance, children can obtain more pleasures from bilingual learning through bilingual reading rooms, bilingual movie theatres, bilingual activity rooms etc.

\section{Form an abundant and natural English language acquisition environment}

English immersion teaching follows the English integrated course, is based on Chinese native culture, combines multi-culture and create an all-English language environment by using the standard English, abundant content and diversified curriculum design. Teachers, which are abundant fountains for language outputs, largely communicate with children with their amiable attitundes. Random language education in daily life is the best opportunity for children to acquire a language. Teachers should grap this opportunity to set examples with standard languages instead of direct correction of errors. Because children's language is not denied directly, they won't feel frustrated and unsuccessful; thus, they will continue actively and proactively participating in dialogue communications; then, teachers can further stimulate children's generative languages. In an English immersion environment, teachers should grasp each opportunity to make a dialogue and communicate with each child so as to lead them to happily learn in this natural, rich and active all-English environment.

\section{Parents and kindergartens cooperate with each other to jointly create an English language environment}

Creating an English environment not only needs teachers' efforts during the half a day of activities in the kindergarten but also cannot be seperated from parents's coordination. If parents fail to create a proper English learning atmosphere at home, children cannot keep their bilingual thinking state, causing that they may forget English. Therefore, the successful implementation of English immersion teaching practices cannot be separated from parents' support and coordination. Teachers shall guide parents to create a favorable audiovisual English environment at home. If some parents cannot speak English or are worried about their nonstandard pronunciation, teachers can guide them to play classical audiovisual English materials for their children everyday and parents can also provide their children with English picture books suitable for their children's ages so as to guarantee children to acquire sufficient English information inputs at home. If parents can speak English, teachers should encourage them to insist on speaking English with their children to create an English learning atmosphere in spite of the nonstandard pronunciation.

\section{Conclusion}

The development of early immersion bilingual teaching for children English begin to take shape in China. In the process of implementing immersion teaching, such strategies were proven to be effective. Despite problems in teachers' professional quality, children's English learning 
environment etc., English immersion bilingual teaching is indeed an excellent teaching mode. As long as teachers integrate the above-mentioned important strategies in teaching and insist on the children-centered principle, the immersion bilingual teaching will certainly yield positive results in China.

\section{Acknowledgments}

This paper is the research result of Study on Early Immersion Bilingual Teaching of Preschool Children English in Xi'an Area of Xi'an Social Science Fund Project. Project No.: 13WL02

\section{References}

[1] Yang Wen. Teaching Methods for Children English. Beijing: Chinse Book Press, 2006(10).

[2] Qiang Haiyan and Zhao Lin. Reference of Canadian Second Language Immersion Teaching in Our Country. Comparative Education Study, 2000(4).

[3] Wu Dinge. Krashen and His Theory of Second Language Acquisition. Modern Foreign Languages. 2009(10).

[4] Cai Xiaodan. Improving the Effectiveness of Teachers; Language Input in English Immersion Teaching for Children. Early Childhood Education: Science of Education, 2010(4). 